\section{俩 Heighten Science \\ P U B L I C I T I O N S Corporation ISSN 2573-1726}

\title{
J oint Functional Screening for Older Adults: Clinical Prevention of Accidental Fall
}

\author{
Balwant S Bains ${ }^{1,2 *}$ \\ ${ }^{1}$ Assistant Professor, School of Physiotherapy, Ainmsa College, Kuala Lumpur, Malaysia \\ ${ }^{2}$ Chairman \& Senior Chief Royal Consultant Physiotherapist, BainsPhysio Group Practice, \\ Kuala Lumpur, Malaysia
}

\begin{abstract}
*Address for Correspondence: Dr. Balwant S Bains, Assistant Professor, School of Physiotherapy, Ainmsa College, Kuala Lumpur, Malaysia,Email: datobains@gmail.com

Submitted: 20 September 2017

Approved: 26 September 2017

Published: 27 September 2017

Copyright: @ 2017 Bains BS. This is an open access article distributed under the Creative Commons Attribution License, which permits unrestricted use, distribution, and reproduction in any medium, provided the original work is properly cited.
\end{abstract}

Keywords: J oint Functional Screening; Older people; Risk of falling; Prevention

\section{Abstract}

As people get older, chronic diseases become an important reason of disability while a decline in physical functions is related to aging among the elders, which may lead to dependency and isolation of the older adults. Body asymmetry and imbalance body alignment can bring added stress to the joint structures that can cause dysfunction of the joint, ligaments, tendons, bursas, and related muscles, which in return brings about problem while walking or during activities of daily living. J oint Functional Screening (J FS) is a systemic clinical examination with clinical reasoning of the entire human joints body, with or without causative limitation to derive a holistic analysis of musculoskeletal system. J FS profile helps to assess body disorder of older people. This clinical screening include documentation of balance of the body, lower and upper body strength, joints flexibility, body composition, and body alignment. This is an innovation build to profile a normal musculoskeletal state to decode any anomaly in an otherwise a normal subject, who might be preparing to take up any activities in one's lifespan that could elicit an injury which could be prevented. J FS could be a useful tool for physiotherapists, exercise therapist or even the personal trainers to screen a body prior to rehabilitative or an exercise program; and this clinical screening is presently a best guidance to prevent risk of fall or injury among individual healthy people and older adult.

\section{Introduction}

Population aging is referred to a distinct phenomenon related to the twentieth century, which undoubtedly remains a significant issue throughout the twenty first century [1]. Population aging was primarily noticed in the developed countries; likewise, the researchers began to notice it in developing countries. Most of countries would have to contend with various levels and time frames of the population aging in not a-too-distant future. As people age, their joints are affected by changes in cartilage and in connective tissue [2]. The cartilage inside a joint becomes thinner, and components of the cartilage (the proteoglycans-substances that help provide the cartilage resilience) become altered, which may make the joint less resilient and more susceptible to damage [3]. Musculoskeletal disorders are common and costly problems for older people. Joints disorders are the main case to increase risk factor of falling. Exercises such as endurance, strength and exergame exercises can help the elderly people to improve performance and functional mobility $[4,5]$. Understanding the importance of exercise on health and falls prevention is critical among older adults, especially those have lower exercise levels [6]. In addition, exercise can effect on psychological aspect and quality of life among elderly people and patients $[7,8]$. In order to have appropriate exercise, knowing the elderly physical character is very important. Previous studies have shown that clinical and general assessment of elderly people can help to prevent injuries and can improve physical performance and quality 
of life $[9,10]$. Study of [11] analysed and Screen 97 older active adults and concluded that functional movement screen can be used to assess functional limitations and asymmetries among elderly. It is important to screen and understand common fundamental aspects of human movement, joints, and muscles dealing throughout a complex activity. The rehabilitation professional must realize that in order to prepare individual's rehabilitation for a wide variety of activities, screening of fundamental complex movements is imperative.

This paper reporting the clinical screening include documentation of balance of the body, lower and upper body strength, joints flexibility, body composition, and body alignment. This is can be an innovation build to profile a normal musculoskeletal state to decode any anomaly in an otherwise a normal subject, who might be preparing to take up any activities in one's lifespan that could elicit an injury which could be prevented. Table 1 illustrated the measurements variables.

\section{Discussion}

Risk of falling is the main issue among elderly population. There are some reasons of fall among elderly people such as environmental, genetic and physiological factors. Previous study showed that around a third of 65-year-old adults fall are faced with fall a minimum once a year [12] and two-thirds of falls in the older adult can be theoretically prevented [13]. Loss of muscle strength in lower body and loss of core muscle stabilization can be lead to decrease balance and posture $[14,15]$. The strength asymmetry of lower body muscles is the factor related the falling among elderly people [16]. The current study mentioned to measure the balance and muscle weakness among elderly people through functional joint screening. Appropriate measurements can prevent risk of injuries and reduce prevalence of fall among older adults. The current study also recommended to measure flexibility of hips, trunk, knee and ankle joint. By ageing trunk muscles flexibility, knee and ankle range of motion were decreased. In addition, lack of the flexibility and range of motion for knee and hip decrease the efficiency of movements and finally lead to increased risk of fall [17]. In the joint functional screening profile, the weight and body composition measurement was mentioned. Overweight or obesity has positive correlation with functional mobility and balance among older people, which can reduce performance and increase risk of fall [18].

\begin{tabular}{|c|c|}
\hline Table 1: Variables and Measurements Tools \\
Variables & Measurement tools \\
\hline Lower body strength & $\begin{array}{c}\text { chair sit to stand test to measure the quadriceps and } \\
\text { hamstring }\end{array}$ \\
\hline Hip Flexibility & straight leg raise (SLR) test \\
\hline Trunk Flexibility & $\begin{array}{c}\text { Sit and Reach Flexibility Test } \\
\text { Trunk Rotation Test }\end{array}$ \\
\hline Knee Flexibility & Active Knee Extension Hamstring Flexibility test \\
\hline Lordosis & Wall Test \\
\hline Scoliosis & Adam's forward bend test \\
\hline Knee hyperextended & Goniometer \\
\hline Body alignment and foot scanning & by Foot levelers machine \\
\hline Body mass index or body composition & In-Body Machine \\
\hline Balance & one leg stance test open and close eye \\
\hline TA tightness & Thomas test \\
\hline Gait and functional mobility & To Meter walking test and TUG \\
\hline Weight & electronic scale \\
\hline
\end{tabular}




\section{Conclusion}

Joint functional screening is a program that could fit into a "missing block" as a prerequisite before a subject takes up any form of exercise or physical activities. Joints Functional Screening can become an asset to the world of rehabilitation and healthy living program as participants and trainer are empowered with the understanding of their own body structures; of their musculoskeletal uniformity; muscle performance before physical activates. JFS also suggests appropriate entry point for safe exercises and enhance muscle strength, endurance, and flexibility. This study are useful for the physiotherapists, exercise therapist, personal trainers by screen body prior to beginning a rehabilitative and exercise program; and this screen package is the best guidance to prevent risk of injuries among individual healthy people. Moreover, this study has significance in community healthcare set up.

\section{References}

1. Harper S. The Challenges of Twenty-First-Century Demography. Challenges of Aging: Springer. 2015; 17-29. Ref.: https://goo.gl/X6dXDe

2. Mosavat M, Mirsanjari M, Omar SZ, Sadeghi H. Bone Health, Exercise and Nutrition. J Adv \& Appl Sci. 2014; 2: 143-156. Ref.: https://goo.gl/apcQ9e

3. Chen $\mathrm{H}$, Zhou X, Fujita H, Onozuka M, Kubo KY. Age-related changes in trabecular and cortical bone microstructure. Int j endocrinol. 2013; 2013: 213234. Ref.: https://goo.gl/ZL7z5s

4. Sadeghi H, Hakim MN, Hamid TA, Amri SB, Razeghi M, et al. The effect of exergaming on knee proprioception in older men: A randomized controlled trial. Arch Gerontol Geriatrics. 2017; 69: 144150. Ref.: https://goo.gl/HMZCKC

5. Thiamwong L, Suwanno J. Effects of Simple Balance Training on Balance Performance and Fear of Falling in Rural Older Adults. Int J Gerontol. 2014; 8: 143-146. Ref.: https://goo.gl/wDGdm7

6. Kosma M, Hondzinski J M, Buchanan DR. Exercise, Health, and Falls Risks among Older African American Women. Int J Kinesiol Sports Sci. 2017; 5: 16-27. Ref.: https://goo.gl/5cSkg8

7. Shakoor E, J ahromi MK, Salesi M, Sadeghi H. The Effects of 10 Weeks Concurrent Aerobic and Strength Exercise on Quality of Life and Resilience of Kidney Transplant Patients. Int J Appl Exercise Physiol. 2015; 4: 1-8. Ref.: https://goo.gl/WBSGZp

8. Zheng XY, Han S, Wang LM, Zhu YH, Zeng L, et al. Quality of Life and Psychology After Living-related Kidney Transplantation From Donors and Recipients in China. Transplantation proceedings. 2014; 46: 3426-3430. Ref.: https://goo.gl/bEQDZU

9. Quinn T, McArthur K, Ellis G, Stott D. Functional assessment in older people. BMJ . 2011; 343: 469473. Ref.: https://goo.gl/HHSWwg

10. Ellis G, Whitehead MA, Robinson D, O'Neill D, Langhorne P. Comprehensive geriatric assessment for older adults admitted to hospital: meta-analysis of randomised controlled trials. Bmj. 2011;343: 6553. Ref.: https://goo.gl/NyDa5M

11. Mitchell UH, J ohnson AW, Vehrs PR, Feland J B, Hilton SC. Performance on the Functional Movement Screen in older active adults. J Sport and Health Sci. 2016; 5: 119-125. Ref.: https://goo.gl/sZAkgf

12. Yamada M, Aoyama T, Nakamura M, Tanaka B, Nagai K, et al. The reliability and preliminary validity of game-based fall risk assessment in community-dwelling older adults. Geriatric nursing (New York, NY). 2011; 32: 188-194. Ref.: https://goo.gl/rqYtzp

13. Inouye SK, Brown CJ, Tinetti ME. Medicare nonpayment, hospital falls, and unintended consequences. New England J ournal of Medicine. 2009; 360: 2390-2393. Ref.: https://goo.gl/gX8xtR

14. Sadeghi H, Shariat A, Asadmanesh E, Mosavat M. The Effects of core stability Exercise on the dynamic balance of volleyball players. Int J Appl Exercise Physiol. 2013; 2: 1-10. Ref.: https://goo.gl/iTFpjv

15. Moreland J D, Richardson J A, Goldsmith CH, Clase CM. Muscle weakness and falls in older adults: a systematic review and meta-analysis. J American Geriatrics Society. 2004; 52: 1121-1129. Ref.: Ref.: https://goo.gl/qiVk6j 
16. LaRoche DP, Cook SB, Mackala K. Strength asymmetry increases gait asymmetry and variability in older women. Medicine and science in sports and exercise. 2012; 44: 2172. Ref.: https://goo.gl/oQLnAn

17. Chiacchiero M, Dresely B, Silva U, DeLosReyes R, Vorik B. The relationship between range of movement, flexibility, and balance in the elderly. Topics in Geriatric Rehabilitation. 2010; 26:148155. Ref.: https://goo.gl/h4i6gx

18. Fjeldstad C, Fjeldstad AS, Acree LS, Nickel KJ , Gardner AW. The influence of obesity on falls and quality of life. Dynamic Medicine. 2008; 7: 4. Ref.: https://goo.gl/jZo4Ra 